\title{
Usefulness of systolic time intervals in differential diagnosis of constrictive pericarditis and restrictive cardiomyopathy ${ }^{1}$
}

\author{
Subhash Khullar² and Richard P. Lewis \\ From the Division of Cardiology, Department of Medicine, Ohio State University College of Medicine, Columbus, \\ Ohio, U.S.A.
}

Systolic time intervals in 15 patients with constrictive pericarditis and seven patients with restrictive cardiomyopathy were compared in order to assess their value in the differential diagnosis of the two disorders. Clinical examination had failed to make the distinction. Right heart catheterization was helpful in diagnosing restriction but failed to differentiate patients with constrictive pericarditis from those with restrictive cardiomyopathy. The systolic time intervals clearly separated the two groups. The PEP/LVET was normal in all patients with constrictive pericarditis (0.34 \pm 0.01$)$ and abnormal in all patients with restrictive cardiomyopathy $(0.70 \pm 0.09, P<0.001)$. In 13 patients (five with restrictive cardiomyopathy and eight with constrictive pericarditis) the results of quantitative left ventricular angiocardiography were available. $A$ high correlation $(r=-0.90, P<0.01)$ between the PEP/LVET and the ejection fraction confirmed the validity of the PEP/LVET as a measure of left ventricular performance in these patients. Thus the systolic time intervals clearly distinguished between constrictive pericarditis and restrictive cardiomyopathy and are a reliable non-invasive technique for making the difficult differential diagnosis.

Restrictive cardiomyopathy may simulate constrictive pericarditis both clinically and haemodynamically (Hetzel, Wood, and Burchell, 1953; Gunner et al., 1955; Clark, Valentine, and Blount, 1956; Goodwin et al., 1961; Wasserman et al., 1962; Burch and Phillips, 1962; Parry and Abrahams, 1963; Shabetai, Fowler, and Fenton, 1965; Ramsey et al., 1970). Whereas diastolic filling of the ventricle is severely impaired in both diseases probably the systolic performance differs. The systolic time intervals are usually normal in constrictive pericarditis (Armstrong, Lewis, and Gotsman, 1973; Lewis and Gotsman, 1973), but they are a sensitive indicator of abnormal left ventricular performance in cardiomyopathy (Weissler, Harris, and Schoenfeld, 1968, 1969; Lewis et al., 1973). Therefore we have reviewed our cases of these two disorders to see whether systolic intervals might provide a reliable non-invasive method of distinguishing one from the other.

\section{Received 7 April 1975.}

1This study was supported in part by a grant from the National Institutes of Health, National Heart and Lung Institute.

'Postdoctoral Fellow for National Institutes of Health.

\section{Patients and methods}

Fifteen patients with constrictive pericarditis and seven with restrictive cardiomyopathy were selected for study. All the patients were symptomatic. At the time of study they were receiving no medication. All underwent right heart catheterization, and left heart catheterization with left ventriculography was performed in 13. The systolic time intervals were routinely obtained the day before catheterization.

The clinical profile of the 15 constrictive pericarditis patients was typical. All underwent successful pericardectomy. None had visible pericardial calcification. The seven patients with restrictive cardiomyopathy were clinically indistinguishable from those with constrictive pericarditis. All presented the strict criteria of restrictive physiology (Fowler, 1971). None had obstructive or purely congestive cardiomyopathy, in which the restrictive features may develop late in the course of the disease. In four of the seven patients the diagnosis was confirmed by finding a normal pericardium at thoracotomy. Another patient had endomyocardial fibroelastosis, confirmed at necropsy, and another had haemochromatosis. The aetiology of the restrictive cardiomyopathy in the remaining patient was not established but his subsequent clinical course was highly suggestive of cardiomyopathy. 
Systolic time intervals were determined by our usual methods (Lewis et al., 1974). In the 13 patients who underwent left heart catheterization and cineventriculography left ventricular volumes were determined from the RAO projection by the area-length method (Sandler and Dodge, 1968; Kasser and Kennedy, 1969). All statistical evaluations were made using standard statistical methods.

\section{Results}

The results of right heart catheterization in the two groups of patients are shown in Table 1. All pressures were raised in both groups and the pressure pulses were typical of restriction. There were no significant differences between the pressures for each group except for the pulmonary artery diastolic pressure, which was slightly higher in the cases of restrictive cardiomyopathy. Notably the mean pulmonary wedge pressure was not significantly different from the mean right atrial pressure in either group. The respiratory variation of peak arterial pressure was slightly greater than normal in each group but did not differ between the groups. The cardiac index was normal in the patients with constrictive pericarditis but was below normal and significantly different in the restrictive cardiomyopathy group.

TABLE 1 Right heart catheterization results (means $\pm S E M$ )

\begin{tabular}{|c|c|c|c|}
\hline & $\begin{array}{l}\text { Constrictive } \\
\text { pericarditis } \\
(n=15)\end{array}$ & $\begin{array}{l}\text { Restrictive } \\
\text { myocardopathy } \\
(n=7)\end{array}$ & $P$ \\
\hline $\begin{array}{l}\text { RA mean (mm Hg) } \\
\text { RVEDP (mm Hg) } \\
\text { PADP (mm Hg) } \\
\text { PCW (mm Hg) } \\
\text { Arterial pulse }\end{array}$ & $\begin{array}{l}13 \pm 1 \\
13 \pm 1 \\
15 \pm 1 \\
16 \pm 2\end{array}$ & $\begin{array}{l}16 \pm 2 \\
17 \pm 2 \\
20 \pm 2 \\
20 \pm 2\end{array}$ & $\begin{array}{l}\text { NS } \\
\text { NS } \\
<0.05 \\
\text { NS }\end{array}$ \\
\hline $\begin{array}{l}\text { pressure (mm Hg) } \\
\text { Cardiac index }\end{array}$ & $17 \pm 5$ & $16 \pm 4$ & $\begin{array}{l}\text { NS } \\
<0.05\end{array}$ \\
\hline
\end{tabular}

$\mathrm{RA}=$ right atrium; $\mathrm{RVEDP}=$ right ventricular end-diastolic pressure; $P A D P=$ pulmonary artery end-diastolic pressure; $\mathrm{PCW}=$ pulmonary capillary wedge pressure.

Conversion from Traditional to SI Units: $1 \mathrm{~mm} \mathrm{Hg} \approx 0.133 \mathrm{kPa}$.

The systolic time intervals are shown in Table 2. The mean values for the $\mathrm{QS}_{2} \mathrm{I}, \mathrm{LVETI}, \mathrm{PEPI}$, and PEP/LVET of the two groups were all significantly different. The PEP/LVET was normal in the constrictive pericarditis cases but highly abnormal in those of restrictive cardiomyopathy. The $\mathrm{QS}_{2} \mathrm{I}$ was normal in the restrictive cardiomyopathy group but significantly short in the cases of constrictive pericarditis.

The Fig. shows the relation between the left ventricular ejection fraction and the PEP/LVET in five patients with restrictive cardiomyopathy and eight with constrictive pericarditis. A high correlation was present $(r=-0.90, P<0.01)$. It is also clear that all constrictive pericarditis patients had a normal ejection fraction $(0.68 \pm 0.02)$ while the ejection fraction was abnormal in all patients with restrictive cardiomyopathy $(0.42 \pm 0.08, \mathrm{P}<0.005)$.

\section{Discussion}

The similarity of the clinical and haemodynamic data in the two groups of patients was expected. The characteristic intracardiac pressures and pulse configurations first described by Bloomfield et al. (1946) and further defined by others later (Hansen, Eskildsen, and Götzsche, 1951; McKusick, 1952; Yu et al., 1953; Wilson et al., 1954) are now known not to be pathognomonic of constrictive pericarditis (Wilson et al., 1954; Lyons, Zuhdi, and Kelly, 1955; Burwell and Robin, 1954; Balchum, McCord, and Blount, 1956). That was so in our series. While the total clinical picture may permit the proper diagnosis, many cases have been reported in which primary myocardial disease masqueraded as constrictive pericarditis (Hetzel et al., 1953; Gunner et al., 1955; Clark et al., 1956; Wasserman et al., 1962; Burch and Phillips, 1962; Parry and Abrahams, 1963; Burwell and Robin, 1954). Among these so-called restrictive cardiomyopathies are endocardial fibroelastosis (Clark et al., 1956; Parry and Abrahams, 1963), cardiac amyloidosis (Hetzel et al., 1953; Gunner et al., 1955), cardiac haemochromatosis (Wasserman et al., 1962), and idiopathic myocardial fibrosis (Hetzel et al., 1953; Burch and Phillips, 1962; Burwell and Robin, 1954).

Certain radiographic and angiographic techniques have been used to discriminate between these two conditions (Figley and Bagshaw, 1957; Steinberg, von Gall, and Finby, 1958; Preger et al., 1965; Desilets, Grollman, and MacAlpin, 1966). The cineangiographic demonstration of a diastolic ventricular snap has not proved specific for constriction (Ramsey et al., 1970; Desilets et al., 1966). Angiographic measurement of cardiac wall thickness as an indication of pericardial thickening is unreliable since it does not clearly distinguish between chamber wall hypertrophy, pericardial effusion, and pericardial thickening (Figley and Bagshaw, 1957). The presence of pericardial calcification alone 
TABLE 2 Systolic time interval results (means $\pm S E M$ )

\begin{tabular}{lllllll}
\hline Group & No. & Age & $Q S_{2} I$ & LVETI & PEPI & PEP/LVET \\
\hline Constrictive pericarditis & 15 & $40 \pm 4$ & $520 \pm 6$ & $401 \pm 4$ & $122 \pm 3$ & $0.34 \pm 0.01$ \\
Restrictive cardiomyopathy & 7 & $39 \pm 5$ & $545 \pm 11$ & $379 \pm 5$ & $171 \pm 11$ & $0.70 \pm 0.09$ \\
P & & NS & $<0.05$ & $<0.005$ & $<0.001$ & $<0.001$ \\
\hline
\end{tabular}

$\mathrm{QS}^{2} \mathrm{I}=$ total electromechanical systole corrected for heart rate; LVETI = left ventricular ejection time corrected or heart rate; PEPI = pre-ejection period.

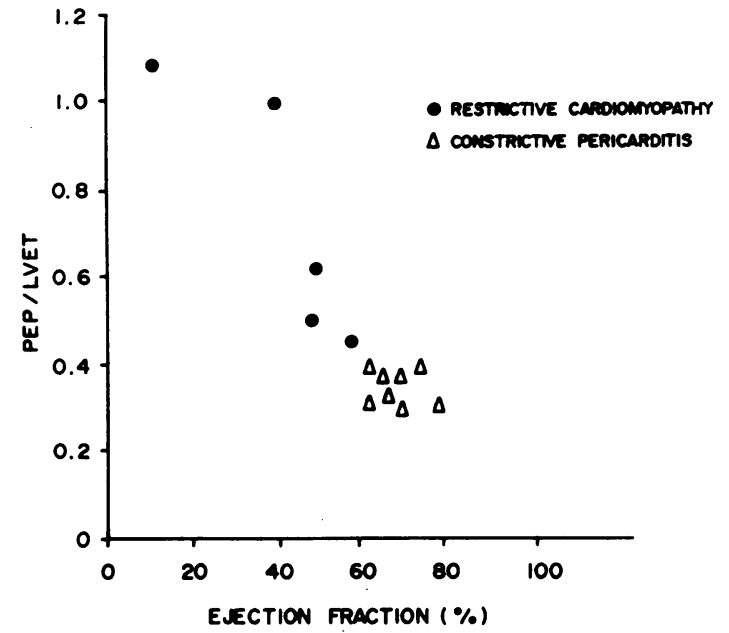

FIG. Relation between the PEP/LVET and left ventricular ejection fraction in eight patients with constrictive pericarditis and five with restrictive cardiomyopathy. Correlation of $-0.90 \quad(P<0.01)$.

is not in itself enough to warrant a diagnosis of constrictive pericarditis (Harvey et al., 1953). Calcification cannot be detected radiographically in at least 40 per cent of patients with constrictive pericarditis (Shabetai et al., 1965). Clearly it is often impossible to distinguish between constrictive pericarditis and restrictive cardiomyopathy by standard diagnostic methods and the diagnosis has been made only by exploratory thoracotomy. Indeed, this was the case in four of our seven patients with restrictive cardiomyopathy. In retrospect, the PEP/LVET was abnormal in all of them and could have aided in the proper diagnosis.

Left ventricular performance in cardiomyopathy is usually significantly abnormal, resulting in a low ejection fraction and an abnormal PEP/LVET (Weissler et al., 1968, 1969; Lewis et al., 1973, 1974). Seemingly systolic performance is nearly always preserved in constrictive pericarditis. This was so in our patients and also in others previously reported (Armstrong et al., 1973; Lewis et al.,
1973), despite subepicardial fibrosis being reported in some patients with advanced constrictive pericarditis (Dines, Edwards, and Burchell, 1958; Levine, 1973). Indeed, in a recent large series studied by Lewis et al. (1973) all 30 patients with constrictive pericarditis had a normal ejection fraction and PEP/LVET despite reduced left ventricular volumes.

The reduced $\mathrm{QS}_{2} \mathrm{I}$ characteristic of the constrictive pericarditis patients in this series is not seen in patients with other types of chronic myocardial disease who are not on drugs (Weissler et al., 1968). It was not noted in our restrictive cardiomyopathy group of patients. A shortened $\mathrm{QS}_{2} \mathrm{I}$, reported in patients with acute myocardial infarction or patients in the first few weeks after cardiac surgery, has been shown to be related to excessive adrenergic activity (Lewis et al., 1972; Boudoulas et al., 1973). Possibly chronic adrenergic hyperactivity is present in patients with constrictive pericarditis. Unlike patients with cardiomyopathy, they have a relatively normal left ventricular myocardium. Consequently they seem to respond to such a stimulus (Nakhjavan and Goldberg, 1970). As a result a normal cardiac output and ejection fraction are maintained despite the impaired diastolic filling. For reasons that are not clear the chronically diseased left ventricle usually shows catecholamine depletion in spite of increased adrenergic activity (Chidsey, Braunwald, and Morrow, 1965). Perhaps this explains the lack of $\mathrm{QS}_{2} \mathrm{I}$ shortening in chronic myocardial disease. This possibility requires further investigation.

Our study has not shown whether the sharp difference in the systolic time intervals in constrictive pericarditis and restrictive cardiomyopathy would exist in milder forms of these disorders. Very probably the systolic intervals would be normal in mild constrictive pericarditis, and also possibly in early cases of restrictive cardiomyopathy. Nevertheless, in patients with clinically severe systemic congestion measurement of the systolic time intervals seems a valuable, noninvasive way of differentiating between cases of constrictive pericarditis and restrictive cardiomyopathy. 


\section{References}

Armstrong, T. G., Lewis, B. S., and Gotsman, M. S. (1973). Systolic time intervals in constrictive pericarditis and primary myocardial disease. American Heart fournal, 85, 6.

Balchum, O. J., McCord, M. C., and Blount, S. G., Jr. (1956). Clinical and haemodynamic pattern in nonspecific myocarditis: comparison with other entities also impairing myocardial efficiency. American Heart fournal, 52, 430.

Bloomfield, R. A., Lauson, H. D., Cournand, A., Breed, E. S., and Richards, D. W., Jr. (1946). Recording of right heart pressures in normal subjects and in patients with chronic pulmonary disease and various types of cardiocirculatory disease. Fournal of Clinical Investigation, 25, 639.

Boudoulas, H., Lewis, R. P., Karayannacos, P. E., and Basko, J. S. (1973). Effect of saphenous vein graft surgery upon left ventricular function. American fournal of Cardiology, 31, 122.

Burch, G. E., and Phillips, J. H. (1962). Methods in diagnostic differentiation of myocardial dilatation from pericardial effusion. American Heart fournal, 64, 266.

Burwell, C. S., and Robin, E. D. (1954). Some points in the diagnosis of myocardial fibrosis. Transactions of the Association of American Physicians, 67, 67.

Chidsey, C. A., Braunwald, E., and Morrow, A. G. (1965). Catecholamine excretion and cardiac stores of Norepinephrine in congestive heart failure. American fournal of Medicine, 39, 442.

Clark, G. M., Valentine, E., and Blount, S. G. (1956). Endocardial fibrosis simulating constrictive pericarditis. New England fournal of Medicine, 254, 349.

Desilets, D. T., Grollman, J. H., Jr., and MacAlpin, R. N. (1966). Cineangiographic demonstration of diastolic snap in constrictive pericarditis. Radiology, 86, 1056.

Dines, D. E., Edwards, J. E., and Burchell, H. B. (1958). Myocardial atrophy in constrictive pericarditis. Mayo Clinic Proceedings, 33, 93.

Figley, M. M., and Bagshaw, M. A. (1957). Angiocardiographic aspects of constrictive pericarditis. Radiology, $69,46$.

Fowler, N. O. (1971). Differential diagnosis of cardiomyopathies. Progress in Cardiovascular Diseases, 14, 113.

Goodwin, J. F., Gordon, H., Hollman, A., and Bishop, M. B. (1961). Clinical aspects of cardiomyopathy. British Medical fournal, 1, 69.

Gunner, R. M., Dillon, R. F., Wallyn, R. J., and Elisberg, E. I. (1955). The physiologic and clinical similarity between primary amyloid of the heart and constrictive pericarditis. Circulation, 12, 827.

Hansen, A. T., Eskildsen, P., and Götzsche, H. (1951). Pressure curves from the right auricle and the right ventricle in chronic constrictive pericarditis. Circulation, 3, 881.

Harvey, R. M., Ferrer, M. I., Cathcart, R. T., Richards, D. W., Jr., and Cournand, A. (1953). Mechanical and myocardial factors in chronic constrictive pericarditis. Circulation, 8, 695.

Hetzel, P. S., Wood, E. H., and Burchell, H. B. (1953) Pressure pulses of the right side of the heart in a case of amyloid disease and in a cäse of idiopathic heart failure simulating constrictive pericarditis. Mayo Clinic Proceedings, 28, 107.

Kasser, I. S., and Kennedy, J. W. (1969). Measurement of left ventricular volumes in man by single-plane cineangiocardiography. Investigative Radiology, 4, 83.

Levine, H. D. (1973). Myocardial fibrosis in constrictive pericarditis, electrocardiographic and pathologic observations. Circulation, 48, 1268.
Lewis, B. S., Armstrong, T. G., Everson, R. C., and Gotsman, M. S. (1973). Predictive value of the systolic time intervals in primary myocardial disease. Chest, 64, 431.

Lewis, B. S., and Gotsman, M. S. (1973). Left ventricular function in systole and diastole in constrictive pericarditis. American Heart fournal, 86, 23.

Lewis, R. P., Boudoulas, H., Forester, W. F., and Weissler, A. M. (1972). Shortening of electromechanical systole as a manifestation of excessive adrenergic stimulation in acute myocardial infarction. Circulation, 46, 856.

Lewis, R. P., Weissler, A. M., Leighton, R. F., and Forester, W. (1974). Systolic time intervals. In Non-invasive Cardiology, p. 301 . Ed. by A. M. Weissler. Grune and Stratton, New York.

Lyons, H. A., Zuhdi, M. N., and Kelly, J. J., Jr. (1955). Pectus excavatum (funnel breast) a cause of impaired ventricular distensibility as exhibited by right ventricular pressure pattern. American Heart fournal, 50, 921.

McKusick, V. A. (1952). Chronic constrictive pericarditis. II. Electrokymographic studies and correlations with roentgenkymography, phonocardiography and right ventricular pressure curves. Bulletin of the fohns Hopkins Hospital, 90, 27.

Nakhjavan, F. K., and Goldberg, H. (1970). Hemodynamic effects of catecholamine stimulation in constrictive pericarditis. Circulation, 42, 487.

Parry, E. H. O., and Abrahams, D. G. (1963). The function of the heart in endomyocardial fibrosis of the right ventricle. British Heart fournal, 25, 619.

Preger, L., Dayem, M. K. A., Goodwin, J. F., and Steiner, R. E. (1965). Angiocardiographic studies of pericardial disease. Lancet, 2, 701.

Ramsey, H. W., Sbar, S., Elliott, L. P., and Eliott, R. S. (1970). The differential diagnosis of restrictive myocardiopathy and chronic constrictive pericarditis without calcification. American fournal of Cardiology, 25, 635.

Sandler, H., and Dodge, H. T. (1968). The use of single plane angiocardiograms for the calculation of left ventricular volume in man. American Heart fournal, 75, 325.

Shabetai, R., Fowler, N. O., and Fenton, J. C. (1965). Restrictive cardiac disease. Pericarditis and the myocardiopathies. American Heart fournal, 69, 271.

Steinberg, I., von Gall, H. V., and Finby, N. (1958). Roentgen diagnosis of pericardial effusion: new angiocardiographic observations. American fournal of Roentgenology, 79, 321.

Wasserman, A. J., Richardson, D. W., Baird, C. L., and Wyso, E. M. (1962). Cardiac hemochromatosis simulating constrictive pericarditis. American fournal of Medicine, 32, 316.

Weissler, A. M., Harris, W. S., and Schoenfeld, C. D. (1968). Systolic time intervals in heart failure in man. Circulation, 37, 149.

Weissler, A. M., Harris, W. S., and Schoenfeld, C. D. (1969). Beside technics for the evaluation of ventricular function in man. American fournal of Cardiology, 23, 577.

Wilson, R. H., Hoseth, W., Sadoff, C., and Dempsey, M. E. (1954). Pathologic physiology and diagnostic significance of the pressure pulse tracings in the heart in patients with constrictive pericarditis and pericardial effusion. American Heart fournal, 48, 671.

Yu, Y. N. G., Lovejoy, F. W., Jr., Joos, H. A., Nye, R. E., and Mahoney, E. B. (1953). Right auricular and ventricular pressure patterns in constrictive pericarditis. Circulation, 7, 102.

Requests for reprints to Dr. Subhash Khullar, Division of Cardiology, Medical College of Ohio, Toledo, Ohio 43614, U.S.A. 